\title{
Anaphylaxie et récepteur de forte affinité des IgE
}

Les immunoglobulines d'isotype E ( $\mathrm{IgE}$ ) et leurs récepteurs constituent l'un des systèmes de défense des mammifères contre les parasites mais certains antigènes peuvent détourner ce système de sa fonction primaire et provoquer une réaction allergique [1]. L'allergie, toutes formes confondues, est la maladie environnementale la plus fréquente puisqu'elle touche plus de $20 \%$ de la population. La progression rapide de la connaissance de la structure et de la fonction des $\operatorname{IgE}$ et de ses récepteurs permet d'espérer le développement prochain de nouvelles thérapeutiques. L'allergie est généralement causée par la surproduction d'IgE et sa manifestation la plus dangereuse, le choc anaphylactique, est souvent liée à une piqûre d'insecte ou à une médication parentérale. Le récepteur de forte affinité des $\operatorname{IgE}$ (FcERl: récepteur du fragment Fc de la chaîne $\varepsilon$ des IgE) est exprimé par les mastocytes, les basophiles, les cellules cutanées de Langerhans, les éosinophiles et certains monocytes [2]. La reconnaissance de l'allergène par les IgE liées à leurs récepteurs FcعRI entraîne la dégranulation et le relargage de médiateurs, tels que l'histamine, et la synthèse de cytokines qui participent directement à l'inflammation. FceRI apparaissant très tôt au cours de l'ontogenèse des mastocytes, alors que les granules ne sont pas encore formés, il a été proposé que ce récepteur joue un rôle important dans le développement de ces cellules en favorisant la production de facteurs de croissance comme l'interleukine 3 .

Deux récepteurs de basse affinité des IgE sont présents à la surface des mastocytes (Fc $\gamma$ RII/CD32 et Fc $\gamma$ RIII/(CD 16) et fixent à la fois les complexes immuns à $\operatorname{IgE}$ et $\operatorname{IgG}$ [3] .

par de nombreuses cellules hématopoḯtiques, peuvent lier les IgE avec une faible affinité, FcERII/C.D23 et Mac-2. Ia variété des récepteurs des IgE et leur présence conjointe à la surface de plusieurs types cellulaires rendent très difficile l'évaluation de leur fonction respective. Pour étudier le rôle du FcERI dans le développement des mastocytes et les réactions allergiques, des lignées de souris, rendues déficientes pour ce récepteur, ont été créées par recombinaison homologue par Dombrowicz et al. (Mokeville, MD, USA) [4]. FceRI est un complexe tétramérique composé de trois sous-unités $(\alpha \beta \gamma 2)$. Puisque seule la forme complète $\alpha \beta \gamma 2$ peut être transportéc jusqu'à la surface cellulaire, la mutagenèse ciblée sur une des trois sousunités est suffisante pour prévenir l'expression du FcERI. Le choix s'est porté sur la sous-unité $\alpha$ qui contient le site de fixation aux $\operatorname{lgE}$, les sous-unités $\beta$ et $\gamma$ intervenant dans la transduction des signaux [5].

L'absence du FcERI chez les souris déficientes ne semble pas affecter dramatiquement l'immunité générale des animaux qui ne montrent aucun signe particulier d'autoimmunité ou de susceptibilité accrue aux infections. De même, la production, le nombre et la fonction des mastocytes n'apparaissent pas dépendre de la présence du FcERI car aucune différence n'a pu être soulignée lors de la comparaison des souris sauvages et mutantes. Quoique très convaincantes, ces observations n'apportent pas d'information sur le rôle du FceRI lors, par exemple, d'une infection parasitaire induisant une forte réponse à $\mathrm{IgE}$. Les souris FceRI ${ }^{-/-}$permettent maintenant de réaliser de telles études et les résultats ne devraient plus tarder. Les estimations de la clairance des $\operatorname{IgE}$ chez les souris
$\mathrm{Fc \varepsilon RI}^{-/-}$montrent que ce récepteur, malgré sa forte affinité pour les IgE, ne joue pas un rôle essentiel dans leur séquestration. Cela renforce l'idée selon laquelle FcERII/CD23 est le principal récepteur impliqué dans ce phénomène ([6] $\left(\mathrm{m} / \mathrm{s} n^{\circ} 10\right.$, vol. 9, p. 1149)).

Dans des conditions expérimentales entraînant une réaction anaphylactique cutanée ou systémique chez les souris sauvages, l'injection d'IgE et de l'antigène n'est pas suivie de manifestation allergique chez les souris FcERI ${ }^{-/-}$. Par conséquent, parmi les différents récepteurs des IgE, un rôle prépondérant dans le déclenchement des réactions allergiques peut être dévolu au FcERl. Même si d'autres conditions d'immunisation devront être testées avant de généraliser l'importance du FcERI dans l'allergie, il est probable que de nouvelles substances interférant avec la fonction de ce récepteur seraient très appréciées par les millions de personnes souffrant d'allergie.

V.L.

1. Sutton BJ, could HJ. The human IgE network. Nature 1993; 366: 421-8.

2. (apron A, Dessaint JP. Présent et futur de l’allergie. médecine/sciences 1990 ; 6 : 958-64. 3. Bonnerot (;, Fridman H. Bases moléculaires de la diversité fonctionnelle des récepteurs des anticorps. méderine/sciences $1993 ; 9$ : $1236-42$.

4. Dombrowicz I), Flamand V, Brigman KK. Koller BH, Kinet JP. Abolition of anaphylaxis by targeted disruption of the high affinity immunoglobulin E receptor $\alpha$ chain gene. Cell 1993; 75 : 969-76.

5. Robertson MW. Phage and E. coli expression of the human high affinity immunoglobulin E receptor alpha subunit ectodomain : domain localization of the IgE bincling site. J Biol Chem 1993; 168: 12736-43.

6. Chen SA. Mechanisms of IgF homeostasis : sequestration of $\mathrm{IgE}$ by murine type $1 \mathrm{FC}$ receptor bearing $\mathrm{B}$ cell lymphomas. / / $\mathrm{mmu}$ nol 1993; 147: 1581-6. 